\title{
Altered nutrition behavior during COVID-19 pandemic lockdown in young adults
}

\author{
Bruno C. Huber ${ }^{1} \cdot$ Julius Steffen $^{1,2}$ (D) Jenny Schlichtiger ${ }^{1} \cdot$ Stefan Brunner $^{1}(\mathbb{C}$
}

Received: 15 May 2020 / Accepted: 29 October 2020 / Published online: 1 December 2020

(c) The Author(s) 2020

\begin{abstract}
Purpose The COVID-19 pandemic and the implemented lockdown strongly impact on everyone's daily life. Stressful situations are known to alter eating habits and increase the risk for obesity. In our study, we aimed to investigate the effect of the lockdown measures on nutrition behavior among young adults.

Methods In this cross-sectional study, we enrolled 1964 voluntary participants from Bavarian universities. All participants were asked to complete an online questionnaire, semi-quantitatively evaluating the amount and type of food before and during pandemic lockdown. Study subjects were inquired to give information about acquisition and food procurement. The primary outcome was the change in food amount, secondary outcomes included alterations of food composition and procurement. Results Our study cohort (mean age $23.3 \pm 4.0$ years, $28.5 \%$ male) had a mean body mass index of $22.1 \pm 4.5 \mathrm{~kg} / \mathrm{m}^{2}$. The overall food amount increased in $31.2 \%$ of participants $(n=610)$ during lockdown and decreased in $16.8 \%(n=328)$. A multinominal regression model revealed that an increased food intake was less likely in male participants (OR, 0.7 [CI 0.6-0.9]) and more likely with increasing BMI (OR, 1.4 [CI 1.3-2.0]), increased sports activity (OR, 1.3 [CI 1.2-1.8]), augmented mental stress (OR 1.4 [1.1-1.7]), and an alteration of alcohol consumption (reduced alcohol amount, OR, 1.4 [CI 1.1-1.7], increased alcohol, OR, 1.9 [CI 1.4-2.5]). Increase in food intake was mainly triggered by consumption of bread (increased in $46.8 \%, n=284$ ) and confectionary (increased in $64.4 \%, n=389$ ).

Conclusion The COVID-19 pandemic lockdown significantly affected eating habits in young adults. Further investigation to evaluate long-term effects on weight change and comorbidities are warranted.
\end{abstract}

Keywords Students $\cdot$ COVID-19 pandemic lockdown $\cdot$ SARS-CoV-2 $\cdot$ Cardiovascular prevention $\cdot$ Dietary habits $\cdot$ Eating behavior

Bruno C. Huber and Julius Steffen have contributed equally to this work.

\section{Electronic supplementary material The online version of this} article (https://doi.org/10.1007/s00394-020-02435-6) contains supplementary material, which is available to authorized users.

Stefan Brunner

Stefan.Brunner@med.uni-muenchen.de

1 Department of Medicine I, Ludwig-Maximilians-University Munich, University Hospital, Campus Innenstadt, Ziemssenstrasse 1, 80336 Munich, Germany

2 Munich Heart Alliance (MHA), Partner Site Munich, DZHK (German Centre for Cardiovascular Research), Marchioninistrasse 15, 81377 Munich, Germany

\section{Introduction}

In December 2019, the new coronavirus SARS-CoV-2 (severe acute respiratory syndrome coronavirus 2 ) emerged in the Chinese city of Wuhan, causing an atypical pneumonia named COVID-19 [1]. From China, the new virus rapidly spread throughout the world and developed into a pandemic. The exponential growth of COVID-19 cases challenged the capacity of health-care systems in an unprecedented manner, so that governments were forced to impose a lockdown with restrictions concerning all areas of life.

On March 21, the German federal state Bavaria imposed a countrywide lockdown involving closure of shops, restaurants, bars, markets and beer gardens (Fig. 1). Alongside the Saarland, it was the first region in Germany to introduce these measures. All German states introduced similar measures one after another, mainly enforcing social distancing 


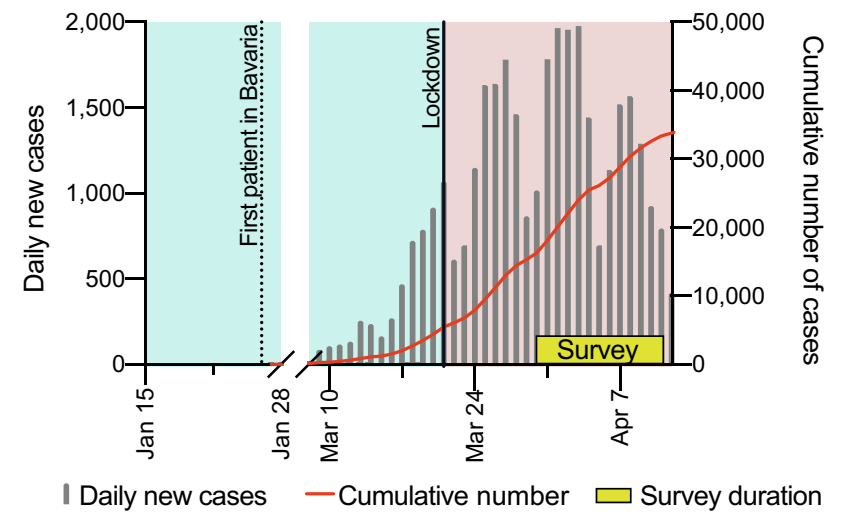

Fig. 1 Daily new cases in Bavaria: timeline showing the number of new confirmed infections with SARS-CoV-2 in Bavaria per day (gray bars) and the cumulative number of cases (red line). The first confirmed case of COVID-19 in Bavaria was on the 27th of January (dotted line), which was also the first case in Germany. Lockdown was implemented by the local authorities in Bavaria on the 21st of March (line). Study participants were asked to compare their eating habits before the lockdown (pastel green area) to during the study period (yellow box) since implementation of the lockdown (pastel red area)

by closure of restaurants, sports and cultural facilities as well as by prohibiting interaction of people from different households. Food acquisition was restricted to supermarkets, grocery stores and delivery services.

Eating behavior is strongly influenced by cultural and social aspects: sharing a meal with friends, family or colleagues is a common habit, which is deeply rooted in our culture and society [2]. It is well known that eating behavior is different when eating alone compared to eating with other people [3]. Furthermore, dietary choices converge with those of close social connections, which may be explained by shared social and cultural expectations and norms [4].

On the other hand, eating behavior has a major impact on health condition and the development of various diseases. Dietary habits are crucial for the development of cardiovascular diseases and even for all-cause mortality. Therefore, a so-called healthy diet plays a key role in both, primary and secondary cardiovascular prevention, and is given a class I recommendation in current guidelines [5]. Further, unhealthy diet patterns may have pro-inflammatory properties with the risk of the development and aggravation of inflammatory diseases including pulmonary infections [6].

So far, data on behavioral and dietary changes during the COVID-19 lockdown are scarce and are mainly limited to observational studies for certain patient cohorts [7] and regions [8]. However, the impact of lockdown measures on healthy young adults has not been addressed yet.

We hypothesized that lockdown measures would influence nutrition behavior among young adults. Therefore, we aimed to explore how food consumption changed during lockdown and to determine which factors impacted these changes.

\section{Methods}

\section{Study oversight}

The COVID-19 Pandemic Lockdown in Young Adults (COLA) trial was a cross-sectional study, performing an online survey among young adults. The ethics committee at the Ludwig-Maximilians-University (LMU) of Munich, Germany, approved the study. Participants of the online survey were informed and consented to all recorded data being used for study purposes. The study was registered at clinicaltrials.gov with the accession identifier NCT04361877.

Primary outcome was the self-reported change in food consumption since introduction of lockdown. Secondary outcomes were the change in food procurement and composition of food.

\section{Survey conduction}

The online survey was organized and conducted as described before. The questionnaire was prepared using EvaSys (Electric Paper Evaluationssysteme GmbH, Lüneburg, Germany). The large-scale online survey consisted of 10 questions with 18 items ( 2 multiple choice items, 3 open ended, and 13 closed-ended items, see Appendix). The first part of the questionnaire collected information on participants' demographics (gender, weight, height, age). The body mass index (BMI) was categorized based on the distribution of the data $\left(<20 \mathrm{~kg} / \mathrm{m}^{2} ; 20-25 \mathrm{~kg} / \mathrm{m}^{2} ;>25 \mathrm{~kg} / \mathrm{m}^{2}\right)$. In the second part, participants answered questions about their lifestyle habits, including food consumption, sports activity, smoking and alcohol consumption since implementation of lockdown in Bavaria (21st of March 2020) compared to the time before on a 3-level scale ("decreased", "unchanged", "increased"). Similarly, they were asked to quantify the overall amount of food consumed as well as different types of food (i.e., bread, dairy, vegetables, fruit, meat, confectionary) they consumed compared to before lockdown. Additionally, changes in food procurement (convenient/delivery/restaurant, cafeteria, home-cooked) were recorded. An English translation of the questionnaire is attached in the Supplementary Appendix.

The questionnaire was distributed via accessible mailing lists of students at LMU Munich $(n=7752)$. Additionally, the main offices of five other Bavarian universities were contacted with the request to forward the survey to their students (students contacted: $n=500$ ). The survey was active for 2 weeks in March and April 2020 (Fig. 1). 


\section{Statistical analysis of survey data}

SPSS version 25 for Windows (SPSS Inc., Chicago, USA), Prism 8 for mac version 8.4.2 (GraphPad Software, San Diego, USA) and Adobe Illustrator version 24.0.3 (Adobe Inc., San Jose, USA) were used for statistical analysis and design of graphs.

Analyses were performed stratified for participants who declared altered eating habits (eating "more" or "less", respectively) since the lockdown. Participants that were over the age of 50 years $(n=16)$ were excluded from the analysis. There were no pre-specified subgroup analyses and the study was intended to be merely descriptive.

For data description, absolute and relative frequencies were calculated. Categorical variables (gender, age, BMI, Corona-test results) were compared using Chi-squared test. Non-categorial variables (age, BMI) were compared using Kruskal-Wallis test. Normal distribution was tested using the Kolmogorov-Smirnov test. Statistical significance was determined at $p<0.05$. Using bivariate analyses, potential influence factors on the outcome variable (changes in food consumption since lockdown). Subsequently, all variables significantly associated with food consumption were included into a multinomial logistic regression model. To adjust for potential confounding, age was included into the regression model, though it did not show a significant correlation with the outcome in the bivariate analyses.

\section{Results}

\section{Study demographics}

A total of 1980 students from six different Bavarian universities participated in the large-scale online survey (response rate, $24 \%)$. Due to the age restriction, $n=16(0.008 \%)$ were excluded from the analyses. Only participants with available data on change in the amount of consumed food were analyzed, which led to a study sample of $n=1957$. Participating students had a mean age of $23.4 \pm 4.0$ years (mean \pm standard deviation), $71.5 \%(n=1,383)$ were female, and most participants had a normal body mass index (BMI) $(22.1 \pm 4.5 \mathrm{~kg} /$ $\mathrm{m}^{2}$ ).

\section{Changes in food procurement due to COVID-19 lockdown}

Since the implementation of lockdown, food procurement has changed dramatically among study participants (Fig. 2). While home-cooked food remains the most frequently reported source of food $(94.8 \%, n=1861$ before, and $98.5 \%$, $n=1935$, during lockdown), the number of people visiting

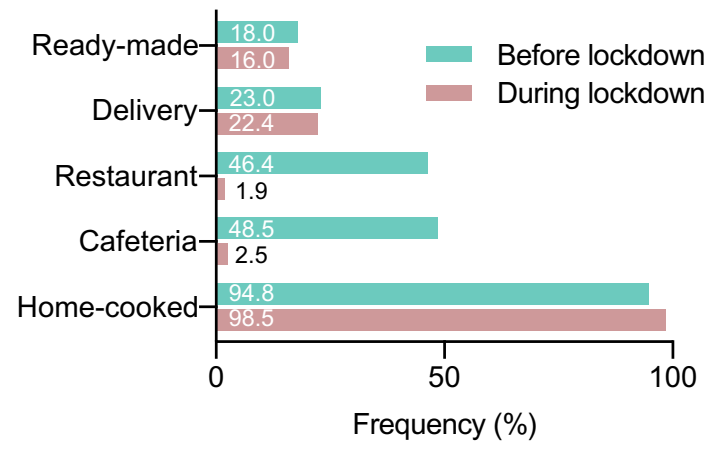

Fig. 2 Food procurement before and during lockdown: Participants were asked in multiple choice questions to name their main ways of food procurement before and during COVID-19 lockdown. Home cooking is the main food source before $(94.8 \%, n=1861)$ and during $(98.5 \%, n=1935)$ lockdown. A dramatic decline was seen in restaurants $(46.4 \%, n=911$ to $1.9 \%, n=37)$ and cafeterias $(48.5 \%, n=953$ $2.5 \%, n=50)$. No changes were seen for food deliveries or readymade food $(18.0, n=353-16.0, n=315)$

restaurants $(46.4 \%, n=911-1.9 \%, n=37)$ or cafeterias $(48.5 \%, n=953-2.5 \%, n=50)$ decreased starkly.

Almost a quarter of participants stated to be demanding food delivery services before lockdown. Although the overall fraction did not change during lockdown $(23.0 \%, n=452$, vs. $22.4 \%, n=440), 234$ (51.8\%) participants stopped ordering food. While obese participants (odds ratio (OR), 1.56 [95\% confidence interval (CI), 1.06-2.25], $p=0.03)$ and smokers (OR, 2.43, [95\% CI 1.53-3.76], $p<0.01$ ) as well as participants with changed amounts of sports activities were more likely to do so, age, gender or the change in amount of food consumed during lockdown had no influence. No predictors for starting to use food delivery could be identified (Supplemental Table S1).

Readymade food was consumed by 353 participants (18.0\%) before and $315(16.0 \%)$ during lockdown. 146 (41.4\%) participants stopped consuming readymade food during lockdown. Abandoning readymade food was positively influenced by an increase in sports activities (OR, 2.30 [95\% CI 1.42-3.87], $p<0.01)$ and a reduced amount of food during lockdown (OR, 1.64 [95\% CI 1.04-2.55], $p=0.03)$. Factors influencing the start of using readymade food included male sex (OR, 1.74 [95\% CI 1.16-2.59], $\mathrm{p}<0.01$ ), $\mathrm{BMI}>25 \mathrm{~kg} / \mathrm{m}^{2}(\mathrm{OR}, 1.99$ [1.19-3.22], $p<0.01)$, decreased sports activities (OR, 2.22 [95\% CI 1.34-3.88], $p<0.01$ ) and increased mental stress (OR, $1.66[1.10-2.55], p=0.02$, see Supplemental Table S2).

\section{Amount of food consumption after lockdown}

Most participants $(52.1 \%, n=1019)$ stated to not have altered the amount of food they consume during lockdown (Fig. 3). Almost one-third of study subjects stated to be 


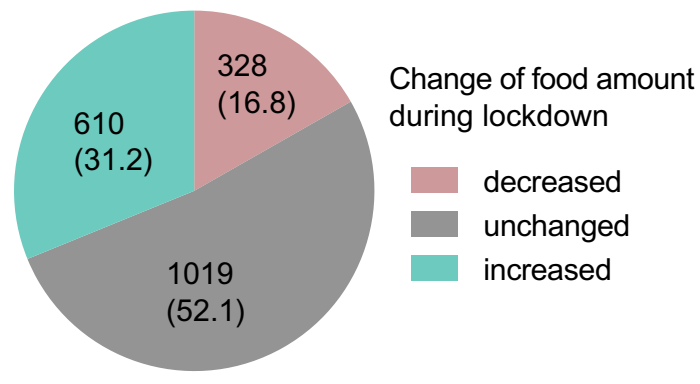

Fig. 3 Quantification of food quantity before and during lockdown: (A) participants were asked if the amount of food intake had changed after the lockdown. Most participants, 52.1\% $(n=1019)$ reported to not have altered their food amount. $16.8 \%(n=328)$ stated to eat less and $31.2 \%(n=610)$ to eat more compared to before the lockdown

eating more $(31.2 \%, n=610)$, whereas $16.8 \%(n=328)$ of the participants ate less compared to the time before lockdown. Characteristics of these three subgroups are given in Supplemental Table S3. Descriptive analyses on changes in consumption (Table 1) showed that an increase was more frequent in women $(n=453,32.8 \%$ vs $n=147,26.6 \%)$ and in the age group of $17-25$ years $(n=480,31.7 \%)$.

\section{Determinants of a changed food amount}

We found that participants with a $\mathrm{BMI}<20 \mathrm{~kg} / \mathrm{m}^{2}$ and people with a normal BMI did not alter their consumed food amount as much as participants with a BMI $>25 \mathrm{~kg} /$ $\mathrm{m}^{2}$, (decreased: $n=58,22.7 \%$, increased: $n=88,34.6 \%$, Fig. 4). The distribution of changes in food consumption was almost similar in participants with a decreased or increased amount of sports activity. An increased alcohol consumption (42.3\%), smoking (42.0\%) and mental stress (35.4\%) during lockdown were associated with eating more.
Table 1 Bivariate analyses of changes in food consumption since lockdown and potential predictor variables

\begin{tabular}{|c|c|c|c|c|c|}
\hline \multicolumn{6}{|c|}{ Changes in food amount } \\
\hline & $n_{\text {missing }}$ & Decreased & Unchanged & Increased & $p$ value \\
\hline & & \multicolumn{4}{|l|}{$\%(n)$} \\
\hline \multicolumn{6}{|l|}{ Gender } \\
\hline Male & 22 & $17.6(97)$ & $55.8(308)$ & $26.6(147)$ & \multirow[t]{2}{*}{$\mathbf{0 . 0 3 1}$} \\
\hline Female & & $16.5(228)$ & $50.8(702)$ & $32.8(453)$ & \\
\hline \multicolumn{6}{|l|}{ Age } \\
\hline $17-25$ & 3 & $16.7(252)$ & $51.6(781)$ & $31.7(480)$ & \multirow[t]{3}{*}{0.770} \\
\hline $26-35$ & & $17.0(71)$ & $53.0(221)$ & $30.0(125)$ & \\
\hline $36-50$ & & $16.7(4)$ & $62.5(15)$ & $20.8(5)$ & \\
\hline \multicolumn{6}{|l|}{ BMI } \\
\hline $\mathrm{BMI}<20 \mathrm{~kg} / \mathrm{m}^{2}$ & 12 & $16.3(74)$ & $54.1(245)$ & $29.6(134)$ & \multirow[t]{3}{*}{0.018} \\
\hline BMI $20-25 \mathrm{~kg} / \mathrm{m}^{2}$ & & $15.8(195)$ & $53.0(655)$ & $31.2(386)$ & \\
\hline $\mathrm{BMI}>25 \mathrm{~kg} / \mathrm{m}^{2}$ & & $22.7(58)$ & $43.0(110)$ & $34.4(88)$ & \\
\hline \multicolumn{6}{|c|}{ Changes in sports activity since lockdown } \\
\hline Decreased & 14 & $18.2(158)$ & $48.8(423)$ & $33.0(286)$ & \multirow[t]{3}{*}{0.001} \\
\hline Unchanged & & $11.4(50)$ & $59.5(262)$ & $29.1(128)$ & \\
\hline Increased & & $18.4(117)$ & $51.3(326)$ & $30.3(193)$ & \\
\hline \multicolumn{6}{|c|}{ Changes in alcohol consumption since lockdown } \\
\hline Decreased & 14 & $18.8(153)$ & $49.1(400)$ & $32.1(262)$ & \multirow[t]{3}{*}{$<0.001$} \\
\hline Unchanged & & $16.4(140)$ & $57.3(489)$ & $26.3(225)$ & \\
\hline Increased & & $12.8(35)$ & $44.9(123)$ & $42.3(116)$ & \\
\hline \multicolumn{6}{|l|}{ Smoking } \\
\hline Yes & 24 & $18.5(22)$ & $39.5(47)$ & $42.0(50)$ & \multirow[t]{2}{*}{0.012} \\
\hline No & & $16.5(300)$ & $52.9(960)$ & $30.5(554)$ & \\
\hline \multicolumn{6}{|l|}{ Mental stress } \\
\hline Decreased & 20 & $17.3(58)$ & $55.8(187)$ & $26.9(90)$ & \multirow[t]{3}{*}{0.015} \\
\hline Unchanged & & 16.4 (137) & $54.3(453)$ & $29.3(244)$ & \\
\hline Increased & & $17.1(131)$ & $47.5(365)$ & 35.4 (272) & \\
\hline
\end{tabular}

Data are given as percentage (absolute numbers). $p$ values from Chi-squared test Bold values indicate statistically significant $p$ values $<0.05$

$B M I$ body mass index 


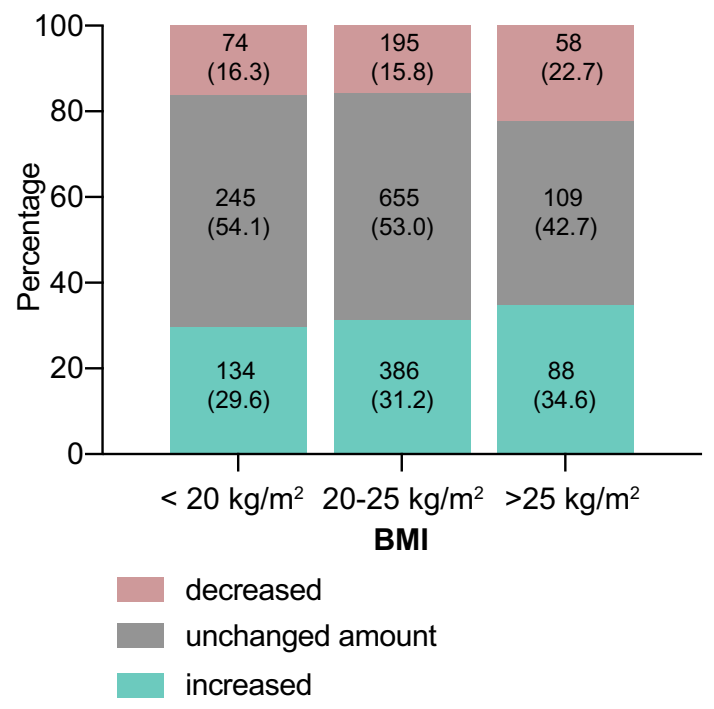

Fig. 4 Alteration of food amount stratified by BMI: participants were stratified by BMI. Numbers are given in Table 2. Alterations in food intake were significantly different for the three categories $(p=0.018)$. More participants with a high BMI $\left(>25 \mathrm{~kg} / \mathrm{m}^{2}\right)(57.3 \%, n=146)$ than with a low BMI $\left(<20 \mathrm{~kg} / \mathrm{m}^{2}\right)(45.9 \%, n=208)$ or a normal BMI $\left(20-25 \mathrm{~kg} / \mathrm{m}^{2}\right)(47.0 \%, n=581)$ changed the amount of food they eat compared to before implementation of lockdown

In a bivariate analysis (Table 1) sex, BMI, changes in sports activity and alcohol consumption as well as smoking and stress showed a significant correlation $\left(p_{\text {chi2 }}<0.05\right)$ with the outcome variable (changes in food amount consumed). The regression model (Table 2, Fig. 5) confirmed the observation that a BMI $>25 \mathrm{~kg} / \mathrm{m}^{2}$ had a significant effect on an altered food amount for both, decreased (odds ratio (OR), 1.8, [95\% confidence interval (CI), 1.3-2.7]), and increased overall food intake (OR, 1.4 [CI 1.3-2.0]). Furthermore, a reduction of sports activity positively affected the chance of a modified food intake (decreased consumption, OR, 1.8 [CI 1.3-2.6], increased consumption, OR, 1.3 [CI 1.2-1.8]). However, the enhancement of sports only impacted a decrease in consumption (OR, 1.9 [CI 1.3-2.8]). For increased consumption, we identified male gender as a protective factor (OR, 0.7 [CI 0.6-0.9]), while changes in alcohol drinking patterns made an increased food intake significantly more likely (reduced alcohol amount, OR, 1.4 [CI 1.1-1.7], increased alcohol, OR, 1.9 [CI 1.4-2.5]).

\section{Change in food categories}

The observed changes in the amount of consumed food are mirrored in the diet of the participants (Fig. 6). The consumption of confectionary and bread increased more clearly in participants consuming an increased amount of food compared to before the lockdown. The confectionary consumption increased in $64.4 \%(n=389)$ and $25.0 \%$ $(n=82)$ of participants for people with an overall increased or decreased food consumption, respectively. This was influenced by the amount of other types of food consumed. Interestingly, while an increase in most food categories was a predictor for higher confectionary consumption, this was the opposite for fruit and vegetable consumption (Supplemental Table S4).

The bread consumption was increased in $46.8 \%(n=284)$ among people with increased food amounts and in only $18.6 \%(n=61)$ among people eating less. Similar numbers were observed for the meat consumption (increase in $24.5 \%$ $(n=146)$ and $6.8 \%(n=22)$, respectively). No relevant differences were found in fruit, vegetable or dairy product consumption. In fact, more than half the participants reported an unchanged amount in these categories. Changes in food categories among people who stated to not have changed the amount of food they consume are presented in Supplemental Fig. S1. There were hardly any differences between men and women (Supplemental Fig. S2). BMI groups had no relevant effect on the types of food consumed (data not shown).

\section{Discussion}

The COVID-19 pandemic dramatically affects daily life for citizens all over the world. To the best of our knowledge, this is the first study investigating the immediate impact of COVID-19 pandemic lockdown on food procurement and dietary habits in a cohort of young adults. In this cohort of almost 2000 young adults, we were able to show the following. 1. Government lockdown significantly altered the amount of food intake. $16.8 \%$ of the participants reported a reduced daily food intake compared to $31.2 \%$ who showed an increase. 2. The food amount was mainly influenced by gender, BMI, sports activity, smoking, mental stress and alcohol consumption. 3. Food procurement and composition changed after implementation of the lockdown, with an enhanced consumption of confectionary.

On the 21st of March, the government in Bavaria implemented a general lockdown and activities outside the place of residence were restricted [9]. To slow the transmission of COVID-19, people were advised to do food shopping as infrequently as possible. However, since the beginning of the crisis, a lot of people reacted with "panic buying" and stocked up groceries [10].

In a first step, we asked our cohort to provide data on the change of daily consumed food amount during COVID19 pandemic. Interestingly, about one-third of our study subjects reported to have increased the daily food amount, which correlates with the current literature [8, 11, 12]. There are several possible explanations for this response. In a multinominal regression, we identified mental stress, 
Table 2 Multinomial regression model of changes in food consumption and potential predictor variables

Changes in food consumption

[reference: constant food consumption]

Decreased food consumption

\begin{tabular}{|c|c|c|c|c|c|}
\hline & $\mathrm{B}$ & OR $[\operatorname{Exp}(B)]$ & $p$ value & Lower $95 \%$ CI & Upper $95 \%$ CI \\
\hline \multicolumn{6}{|l|}{ Sex [ref.: female] } \\
\hline Male & -0.042 & 0.959 & 0.782 & 0.710 & 1.293 \\
\hline \multicolumn{6}{|c|}{ Age [ref.: 36-50 years] } \\
\hline $17-25$ & -0.215 & 0.806 & 0.721 & 0.248 & 2.626 \\
\hline $26-35$ & -0.253 & 0.776 & 0.679 & 0.234 & 2.574 \\
\hline \multicolumn{6}{|c|}{$\mathrm{BMI}^{1}\left[\right.$ ref.: BMI $\left.20-25 \mathrm{~kg} / \mathrm{m}^{2}\right]$} \\
\hline $\mathrm{BMI}<20 \mathrm{~kg} / \mathrm{m}^{2}$ & 0.013 & 1.013 & 0.939 & 0.734 & 1.398 \\
\hline $\mathrm{BMI}>25 \mathrm{~kg} / \mathrm{m}^{2}$ & 0.594 & 1.811 & 0.002 & 1.248 & 2.672 \\
\hline \multicolumn{6}{|c|}{ Changes in sports activity since lockdown [ref.: constant] } \\
\hline Reduced & 0.607 & 1.835 & 0.001 & 1.274 & 2.643 \\
\hline Increased & 0.636 & 1.889 & 0.001 & 1.293 & 2.762 \\
\hline \multicolumn{6}{|c|}{ Changes in alcohol consumption since lockdown [ref.: constant] } \\
\hline Reduced & 0.252 & 1.286 & 0.074 & 0.976 & 1.695 \\
\hline Increased & -0.039 & 0.961 & 0.857 & 0.625 & 1.478 \\
\hline \multicolumn{6}{|c|}{ Smoking [ref.: non-Smoker] } \\
\hline Smoker & 0.223 & 1.250 & 0.431 & 0.717 & 2.179 \\
\hline \multicolumn{6}{|c|}{ Mental stress [ref.: constant] } \\
\hline Reduced & 0.040 & 1.041 & 0.829 & 0.724 & 1.496 \\
\hline Increased & 0.163 & 1.177 & 0.266 & 0.883 & 1.568 \\
\hline \multicolumn{6}{|c|}{ Increase in food consumption } \\
\hline & B & OR $[\operatorname{Exp}(B)]$ & $p$ value & Lower $95 \%$ CI & Upper $95 \%$ CI \\
\hline \multicolumn{6}{|l|}{ Sex [ref.: female] } \\
\hline Male & -0.137 & 0.728 & 0.013 & 0.567 & 0.936 \\
\hline \multicolumn{6}{|c|}{ Age [ref.: $36-50$ years] } \\
\hline $17-25$ & 0.490 & 1.632 & 0.380 & 0.547 & 4.867 \\
\hline $26-35$ & 0.313 & 1.368 & 0.579 & 0.452 & 4.138 \\
\hline \multicolumn{6}{|c|}{$\mathrm{BMI}^{1}\left[\right.$ ref.: BMI $\left.20-25 \mathrm{~kg} / \mathrm{m}^{2}\right]$} \\
\hline $\mathrm{BMI}<20 \mathrm{~kg} / \mathrm{m}^{2}$ & -0.132 & 0.876 & 0.319 & 0.675 & 1.136 \\
\hline $\mathrm{BMI}>25 \mathrm{~kg} / \mathrm{m}^{2}$ & 0.356 & 1.427 & $\mathbf{0 . 0 3 2}$ & 1.032 & 1.974 \\
\hline \multicolumn{6}{|c|}{ Changes in sports activity since lockdown [ref.: constant] } \\
\hline Reduced & 0.293 & 1.340 & $\mathbf{0 . 0 3 5}$ & 1.022 & 1.758 \\
\hline Increased & 0.137 & 1.146 & 0.354 & 0.859 & 1.531 \\
\hline \multicolumn{6}{|c|}{ Changes in alcohol consumption since lockdown [ref.: constant] } \\
\hline Reduced & 0.0302 & 1.353 & 0.010 & 1.074 & 1.704 \\
\hline Increased & 0.620 & 1.859 & 0.000 & 1.362 & 2.538 \\
\hline \multicolumn{6}{|c|}{ Smoking [ref.: non-Smoker] } \\
\hline Smoker & 0.417 & 1.518 & 0.062 & 0.979 & 2.353 \\
\hline \multicolumn{6}{|c|}{ Mental stress [ref.: constant] } \\
\hline Reduced & -0.073 & 0.929 & 0.641 & 0.682 & 1.266 \\
\hline Increased & 0.304 & 1.355 & 0.010 & 1.076 & 1.706 \\
\hline
\end{tabular}

Bold values indicate statistically significant $p$ values $<0.05$

$O R$ odds ratio, $C I$ confidence interval, $B M I$ body mass index

BMI $>25 \mathrm{~kg} / \mathrm{m}^{2}$, altered sports activity and altered alcohol consumption as risk factors for increased eating.
First, changes in eating patterns are partly triggered by augmented psychological stress during the COVID-19 crisis 


\section{Decrease in food amount}

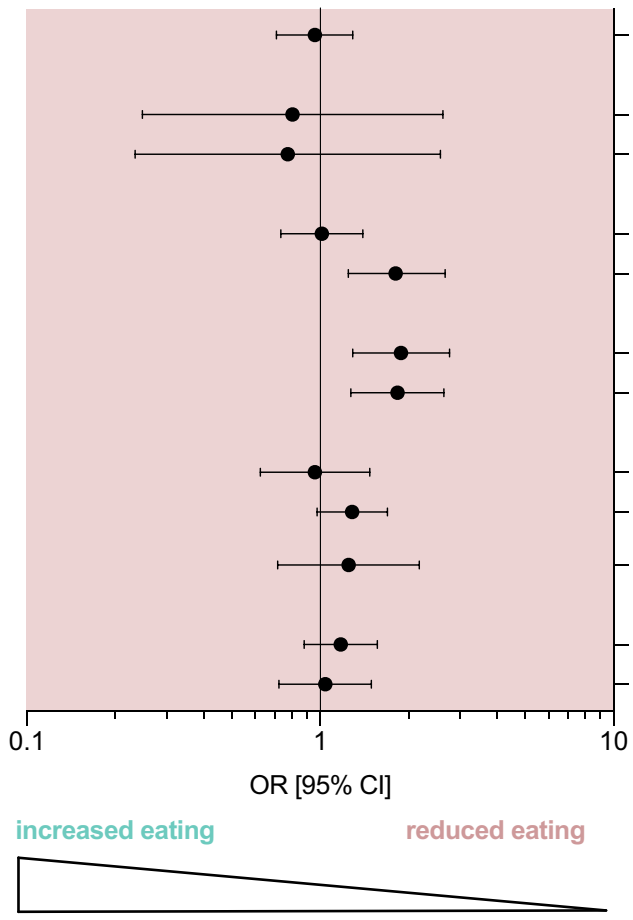

Increase in food amount

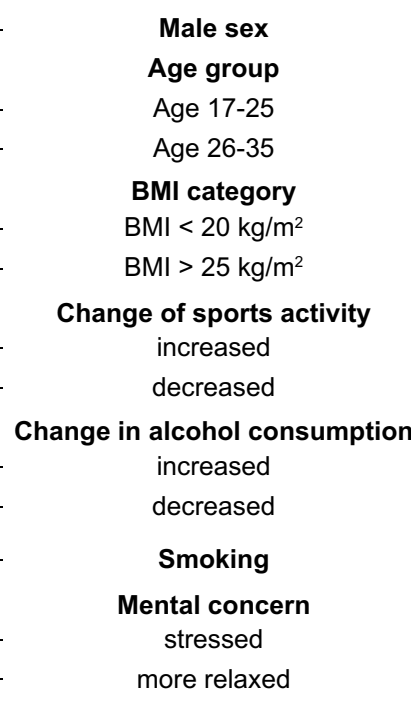

0.1

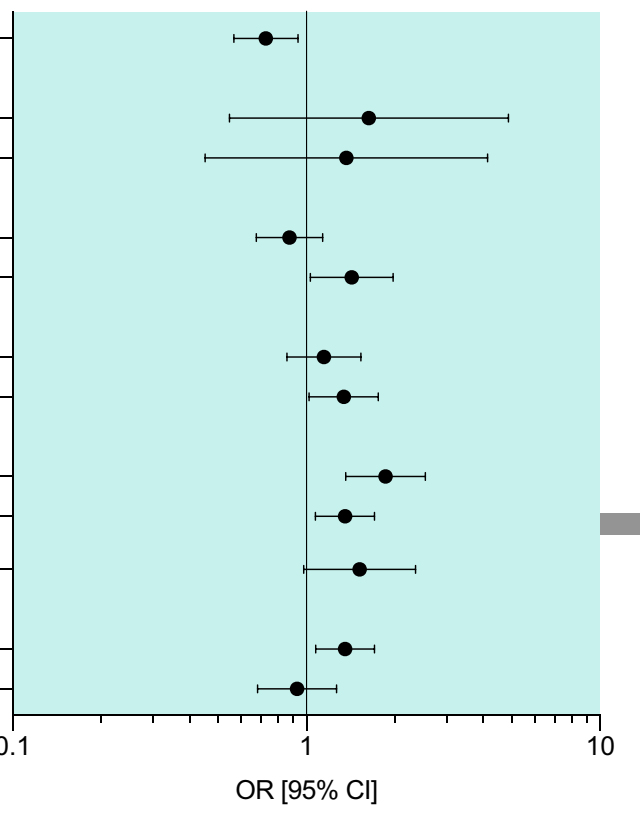

reduced eating
Fig. 5 Forest plots depicting odds ratios for variables impacting a decreased or an increased food amount. Subgroups of decreased and increased overall food intake were referenced to a constant food intake. Odds ratios (OR) and 95\% confidence intervals (CI) are depicted with balls and bars, respectively, for the different categories. Changes in food consumption were promoted by gender, BMI, sports activity, alcohol consumption and smoking status. Detailed data and reference categories are shown in Table 2
[13]. Our results show a higher risk for an increased food intake in people who state to be mentally stressed. Similarly, Pellegrini et al. could demonstrate a weight gain during the COVID-19 lockdown of over $3 \mathrm{~kg}$ in patients with self-perceived anxiety during the crisis [14]. Data from the Midlife in the United States (MIDUS) study containing a representative cohort of adults revealed that psychosocial stress contributes to changes in dietary behaviors that again results in significant weight gain [15]. Interestingly, weight gain in that cohort was more pronounced in people with higher body mass indexes.

In our data, participants with BMI $>25 \mathrm{~kg} / \mathrm{m}^{2}$ reported more frequently to have increased food intake compared to the subgroups of participants with a normal or reduced BMI. In the regression model, BMI $>25 \mathrm{~kg} / \mathrm{m}^{2}$ was found to be an independent risk factor for an increased food intake (OR 1.8 [CI 1.3-2.7]). Similar to the former MIDUS study, individuals with a high BMI have been shown to increase their food consumption considerably and gained more weight during COVID-19 lockdown [11]. However, this contrasts with the comprehensive analysis of Di Renzo et al. who reported no difference in BMI in study participants eating more [8].

Nevertheless, a higher BMI has been found to be associated with a lower level of sports activity and sports activity is an important factor for a reduction and maintenance of body weight $[16,17]$. In two cohort studies of obese patients in Italy during COVID-19 lockdown, a further decrease in sports activity was observed and resulted in a significant additional weight gain [7, 14]. In line with this, in our study, a self-reported modification of sports activity was associated with lower food intake and an increase in sports activity was found to predict a lower food intake (OR 1.9 [CI 1.3-2.8]).

These data are also important from a clinical perspective, since obesity significantly increases the risk of developing severe pneumonia in COVID-19 infections [18], and obesity is a common risk factor for respiratory failure leading to invasive mechanical ventilation [19].

Previous studies have assessed the impact of natural disasters on food and nutrition management [20]. A retrospective cohort study evaluated the impact of the devastating earthquake and tsunami in Japan in 2011 in preschool children. They found a significant increase in BMIs 1 month after the earthquake [21]. Moreover, in 200 adult subjects, results of physical examinations and laboratory tests after the Great East Japan Earthquake revealed higher values of body weight, body mass index, waist circumference and HbA1c compared with pre-earthquake levels [22]. 
Fig. 6 Change in food categories in participants with an increased or decreased overall food intake. In all participants, bread and confectionary intake changed more than other food categories. Among people reporting to have increased their food amount, confectionary consumption increased more compared to people who reported to have decreased their total food amount $(64.4 \%$, $n=389$, vs. $25.0 \%, n=82$, $p<0.001)$. Significant differences were also seen for the amount of meat and bread consumed. No differences were observed for vegetables or fruits. Dairy product consumption was affected the least (eat less, $57.2 \%, n=187$, vs. eat more, $59.6 \%, n=362$, did not change the amount)

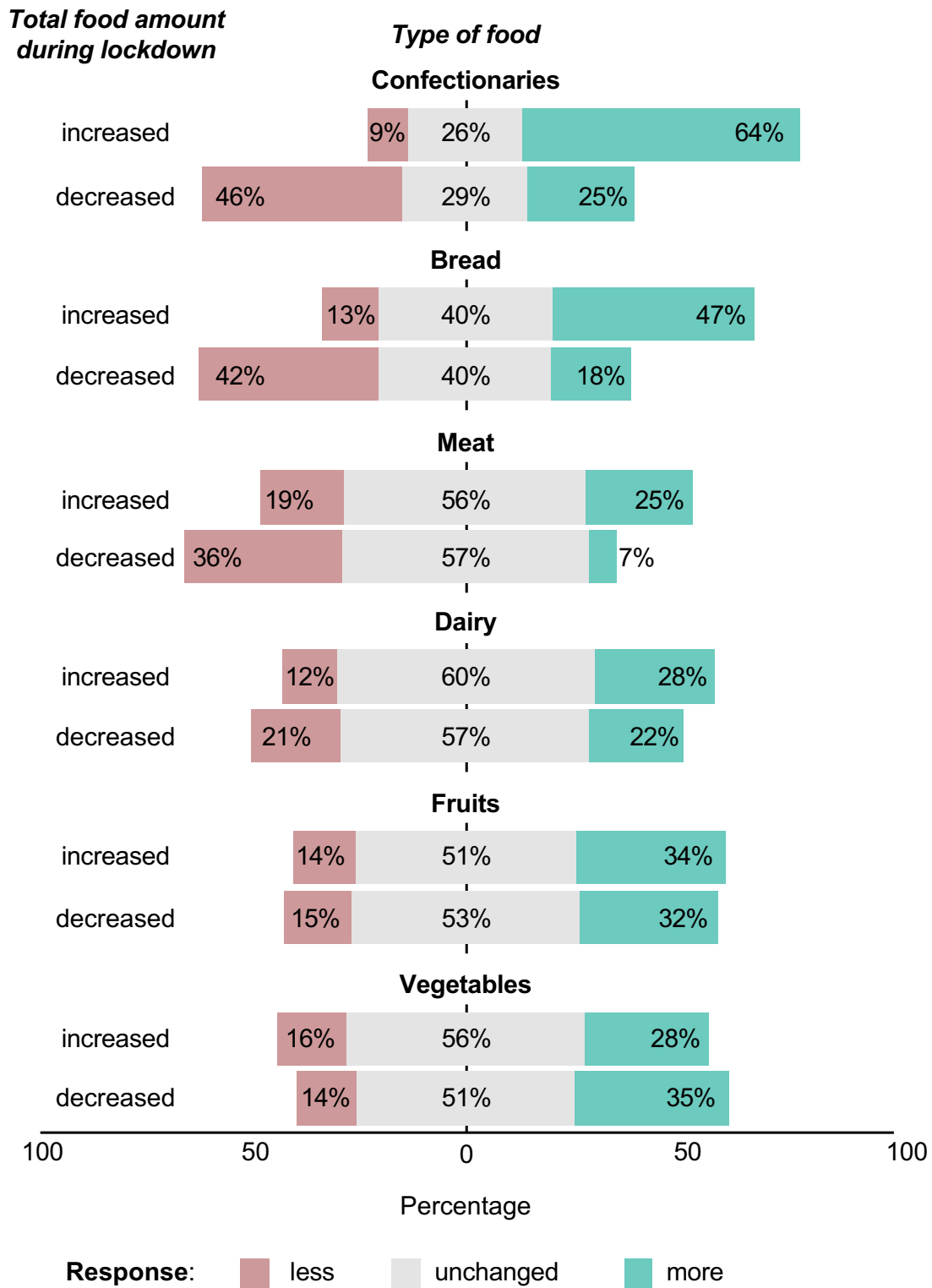

Another important information from our subjects is the change of food procurement during the pandemic lockdown. Most subjects reported to self-prepare and cook food at home-as they did before lockdown implementation. Other studies could demonstrate a reduction of delivery food intake [8]. Interestingly, in this study, there was no relevant change in the overall frequency of people getting their food from a takeaway or from restaurants offering a delivery service, but a considerable fraction of participants changed their attitude towards readymade food and food delivery services. Male sex, high BMI and decreased sports activities during lockdown were identified as factors promoting the consumption of readymade food.

Among participants of our study reporting to consume more food after lockdown, there was a detectable shift toward carbohydrate-containing food such as confectionaries and bread. This observation has been made in Italy [12] and Poland [11], too. Unfortunately, our data also indicate that increased confectionary consumption had a higher chance of decreased fruit and vegetable consumption. An increase of carbohydrate consumption may promote cardiovascular diseases, obesity, and diabetes [23]. A previous large cohort study could further demonstrate a strong association of a high caloric diet with higher risk of all-cause mortality [24]. However, long-term effects of the observed nutrition shift on morbidity and mortality are not assessable at this time.

Our study has some limitations. It is a cross-sectional study and the resulting changes in weight/BMI in this study cohort cannot be reassessed in the future. Conclusions drawn are based on self-reported amounts of food consumption. Therefore, the analyses included in the study need to be interpreted with caution. The analysis focused on young 
adults who are registered at Bavarian Universities and does not fully represent young adults throughout Germany. However, the homogenous study cohort provides valuable insights into COVID-19 pandemic related changes of food and nutrition management in healthy young individuals in Germany.

In summary, we were able to show for the first time a change in the food amount, its underlying determinants, acquisition of food as well as food composition among healthy young adults during the COVID-19 crisis. Further longitudinal studies investigating long-term effects are warranted.

Acknowledgements We would like to give special thanks to Monika Baylacher for her support throughout the study.

Author contributions All authors contributed to the study conception and design. Material preparation, data collection and analysis were performed by Stefan Brunner, Julius Steffen and Jenny Schlichtiger. The first draft of the manuscript was written by Bruno Huber and Julius Steffen and all authors commented on previous versions of the manuscript. All authors read and approved the final manuscript.

Funding Open Access funding enabled and organized by Projekt DEAL. None of the authors of this study received extra funding. This study was funded by institutional funds of the Department of Medicine I, University Hospital Munich.

\section{Compliance with ethical standards}

Conflict of interest The authors declare that they have no conflict of interest.

\section{Consent to participate}

All persons gave their informed consent prior to their inclusion in the study.

Ethics approval Conduction of the study has been approved by the ethics committee at LMU Munich medical faculty (Ethikkommission der Medizinischen Fakultät, approval number 20-268 KB). The study was performed in accordance with the ethical standards laid down in the 1964 Declaration of Helsinki and its later amendments.

Informed consent All persons gave their informed consent prior to their inclusion in the study.

Availability of data and material Raw data can be provided upon email request.

Open Access This article is licensed under a Creative Commons Attribution 4.0 International License, which permits use, sharing, adaptation, distribution and reproduction in any medium or format, as long as you give appropriate credit to the original author(s) and the source, provide a link to the Creative Commons licence, and indicate if changes were made. The images or other third party material in this article are included in the article's Creative Commons licence, unless indicated otherwise in a credit line to the material. If material is not included in the article's Creative Commons licence and your intended use is not permitted by statutory regulation or exceeds the permitted use, you will need to obtain permission directly from the copyright holder. To view a copy of this licence, visit http://creativecommons.org/licenses/by/4.0/.

\section{References}

1. Li Q, Guan X, Wu P, Wang X, Zhou L, Tong Y, Ren R, Leung KSM, Lau EHY, Wong JY, Xing X, Xiang N, Wu Y, Li C, Chen Q, Li D, Liu T, Zhao J, Liu M, Tu W, Chen C, Jin L, Yang R, Wang Q, Zhou S, Wang R, Liu H, Luo Y, Liu Y, Shao G, Li H, Tao Z, Yang Y, Deng Z, Liu B, Ma Z, Zhang Y, Shi G, Lam TTY, Wu JT, Gao GF, Cowling BJ, Yang B, Leung GM, Feng Z (2020) Early transmission dynamics in Wuhan, China, of novel coronavirus-infected pneumonia. N Engl J Med 382(13):1199-1207. https ://doi.org/10.1056/NEJMoa2001316

2. Oh A, Erinosho T, Dunton G, Perna FM, Berrigan D (2014) Cross-sectional examination of physical and social contexts of episodes of eating and drinking in a national sample of US adults. Public Health Nutr 17(12):2721-2729. https://doi.org/10.1017/ S1368980013003315

3. Herman CP, Roth DA, Polivy J (2003) Effects of the presence of others on food intake: a normative interpretation. Psychol Bull 129(6):873-886. https://doi.org/10.1037/0033-2909.129.6.873

4. Cruwys T, Bevelander KE, Hermans RC (2015) Social modeling of eating: a review of when and why social influence affects food intake and choice. Appetite 86:3-18. https://doi.org/10.1016/j. appet.2014.08.035

5. Piepoli MF, Hoes AW, Agewall S, Albus C, Brotons C, Catapano AL, Cooney MT, Corra U, Cosyns B, Deaton C, Graham I, Hall MS, Hobbs FDR, Lochen ML, Lollgen H, Marques-Vidal P, Perk J, Prescott E, Redon J, Richter DJ, Sattar N, Smulders Y, Tiberi M, van der Worp HB, van Dis I, Verschuren WMM, Binno S, Group ESCSD (2016) 2016 European guidelines on cardiovascular disease prevention in clinical practice: the sixth joint task force of the European Society of Cardiology and other societies on cardiovascular disease prevention in clinical practice (constituted by representatives of 10 societies and by invited experts) developed with the special contribution of the European Association for Cardiovascular Prevention \& Rehabilitation (EACPR). Eur Heart J 37(29):2315-2381. https://doi.org/10.1093/eurheartj/ehw106

6. Messina G, Polito R, Monda V, Cipolloni L, Di Nunno N, Di Mizio G, Murabito P, Carotenuto M, Messina A, Pisanelli D, Valenzano A, Cibelli G, Scarinci A, Monda M, Sessa F (2020) Functional role of dietary intervention to improve the outcome of COVID-19: a hypothesis of work. Int J Mol Sci. https://doi. org/10.3390/ijms21093104

7. Pietrobelli A, Pecoraro L, Ferruzzi A, Heo M, Faith M, Zoller T, Antoniazzi F, Piacentini G, Fearnbach SN, Heymsfield SB (2020) Effects of COVID-19 lockdown on lifestyle behaviors in children with obesity living in Verona, Italy: a longitudinal study. Obesity (Silver Spring). https://doi.org/10.1002/oby.22861

8. Di Renzo L, Gualtieri P, Pivari F, Soldati L, Attina A, Cinelli G, Leggeri C, Caparello G, Barrea L, Scerbo F, Esposito E, De Lorenzo A (2020) Eating habits and lifestyle changes during COVID19 lockdown: an Italian survey. J Transl Med 18(1):229. https:// doi.org/10.1186/s12967-020-02399-5

9. https://www.faz.net/aktuell/politik/inland/coronavirus-in-bayer n-soeder-kuendigt-ausgangsbeschraenkungen-an-16688175.html (2020).

10. dpa (2020) https://www.welt.de/regionales/bayern/article206 542477/Wieder-mehr-Hamsterkaeufe-in-Bayern.html.

11. Sidor A, Rzymski P (2020) Dietary choices and habits during COVID-19 lockdown: experience from Poland. Nutrients. https ://doi.org/10.3390/nu12061657

12. Scarmozzino F, Visioli F (2020) Covid-19 and the subsequent lockdown modified dietary habits of almost half the population in an Italian sample. Foods. https://doi.org/10.3390/foods90506 75 
13. Torres SJ, Nowson CA (2007) Relationship between stress, eating behavior, and obesity. Nutrition 23(11-12):887-894. https://doi. org/10.1016/j.nut.2007.08.008

14. Pellegrini M, Ponzo V, Rosato R, Scumaci E, Goitre I, Benso A, Belcastro S, Crespi C, DeMichieli F, Ghigo E, Broglio F, Bo S (2020) Changes in weight and nutritional habits in adults with obesity during the "Lockdown" period caused by the COVID-19 virus emergency. Nutrients. https://doi.org/10.3390/nu12072016

15. Block JP, He Y, Zaslavsky AM, Ding L, Ayanian JZ (2009) Psychosocial stress and change in weight among US adults. Am J Epidemiol 170(2):181-192. https://doi.org/10.1093/aje/kwp104

16. Millard LAC, Tilling K, Lawlor DA, Flach PA, Gaunt TR (2017) Physical activity phenotyping with activity bigrams, and their association with BMI. Int J Epidemiol 46(6):1857-1870. https:// doi.org/10.1093/ije/dyx093

17. Chin SH, Kahathuduwa CN, Binks M (2016) Physical activity and obesity: what we know and what we need to know. Obes Rev 17(12):1226-1244. https://doi.org/10.1111/obr.12460

18. Calder PC, Carr AC, Gombart AF, Eggersdorfer M (2020) Optimal nutritional status for a well-functioning immune system is an important factor to protect against viral infections. Nutrients. https ://doi.org/10.3390/nu12041181

19. Goyal P, Choi JJ, Pinheiro LC, Schenck EJ, Chen R, Jabri A, Satlin MJ, Campion TR Jr, Nahid M, Ringel JB, Hoffman KL, Alshak MN, Li HA, Wehmeyer GT, Rajan M, Reshetnyak E, Hupert N, Horn EM, Martinez FJ, Gulick RM, Safford MM (2020) Clinical characteristics of Covid-19 in New York City. N Engl J Med. https ://doi.org/10.1056/NEJMc2010419

20. Tsuboyama-Kasaoka N, Purba MB (2014) Nutrition and earthquakes: experience and recommendations. Asia Pac J Clin Nutr 23(4):505-513. https://doi.org/10.6133/apjcn.2014.23.4.23
21. Yokomichi H, Zheng W, Matsubara H, Ishikuro M, Kikuya M, Isojima T, Yokoya S, Tanaka T, Kato N, Chida S, Ono A, Hosoya M, Tanaka S, Kuriyama S, Kure S, Yamagata Z (2016) Impact of the great east Japan earthquake on the body mass index of preschool children: a nationwide nursery school survey. BMJ Open 6(4):e010978. https://doi.org/10.1136/bmjopen-2015-010978

22. Tsubokura M, Takita M, Matsumura T, Hara K, Tanimoto T, Kobayashi K, Hamaki T, Oiso G, Kami M, Okawada T, Tachiya H (2013) Changes in metabolic profiles after the Great East Japan Earthquake: a retrospective observational study. BMC Public Health 13:267. https://doi.org/10.1186/1471-2458-13-267

23. Khan TA, Sievenpiper JL (2016) Controversies about sugars: results from systematic reviews and meta-analyses on obesity, cardiometabolic disease and diabetes. Eur J Nutr 55(Suppl 2):25-43. https://doi.org/10.1007/s00394-016-1345-3

24. Dehghan M, Mente A, Zhang X, Swaminathan S, Li W, Mohan V, Iqbal R, Kumar R, Wentzel-Viljoen E, Rosengren A, Amma LI, Avezum A, Chifamba J, Diaz R, Khatib R, Lear S, LopezJaramillo P, Liu X, Gupta R, Mohammadifard N, Gao N, Oguz A, Ramli AS, Seron P, Sun Y, Szuba A, Tsolekile L, Wielgosz A, Yusuf R, Hussein Yusufali A, Teo KK, Rangarajan S, Dagenais G, Bangdiwala SI, Islam S, Anand SS, Yusuf S, Prospective Urban Rural Epidemiology Study i (2017) Associations of fats and carbohydrate intake with cardiovascular disease and mortality in 18 countries from five continents (PURE): a prospective cohort study. Lancet 390(10107):2050-2062. https://doi.org/10.1016/ S0140-6736(17)32252-3 